\title{
EVENTOS EXTREMOS DE PRECIPITAÇÃO EM GILBUÉS-PIAUÍ: IMPACTOS NA PAISAGEM E POTENCIALIZAÇÃO DO PROCESSO DE ARENIZAÇÃO
}

\author{
Ivamauro Ailton de Sousa Silva ${ }^{(a)}$ \\ ${ }^{(a)}$ Doutorando em Geografia, Instituto de Geociências, Universidade Federal do Rio Grande do Sul, UFRGS, \\ ivamauro@hotmail.com
}

\section{Eixo: Climatologia em diferentes níveis escalares: mudanças e variabilidades}

\begin{abstract}
Resumo
As características pluviométricas e suas variações inesperadas provocam impactos, principalmente em áreas com fragilidade ambiental. Nesta pesquisa, investigou-se a ocorrência de eventos extremos de precipitação e a influência da variabilidade pluviométrica na gênese e potencialização do processo de arenização, no município de Gilbués, Piauí. Para isso, a pesquisa foi elaborada, por revisão bibliográfica e pela coleta e análise de dados meteorológicos obtidos através da Estação Hidroclimática da Superintendência do Desenvolvimento do Nordeste. Como resultados, o artigo elucida, que as condições climáticas, são bem dinâmicas e possui alta variabilidade pluviométrica e os eventos extremos de precipitação ocorrem com frequência e são capazes de alterar as características ambientais e acelerar os processos erosivos, já que a área em questão apresenta vulnerabilidade. A interação entre variabilidade climática, eventos extremos de precipitação, dinâmica hídrica e escoamento superficial, atuam na remobilização, remoção, transportee deposição do material arenoargiloso, promovendo extensas áreas com solo exposto avermelhado.
\end{abstract}

Palavras chave: Eventos Extremos; Precipitação; Gilbués; Arenização.

\section{Introdução}

Os eventos meteorológicos extremos são aspectos integrantes da variabilidade climática e sua frequência e intensidade podem variar de acordo com os fenômenos climáticos (El Niño e à La Niña), assim como variações sazonais associadas aos sistemas atmosféricos, bem como a atividade da Zona de Convergência do Atlântico Sul (ZCAS), Zonade Convergência Intertropical (ZCIT) e do Jato de Baixos Níveis da América do Sul.

A precipitação é uma das variáveis meteorológicas mais consideradas para os estudos climáticos e complexas para relizar uma análise acerca de eventos extremos. Tal importância reside em seu regime e também na ocorrência de episódios excepcionais, que desencadeiam processos erosivos no solo, provocando significativos prejuízos socioeconômicos e ainda modificações ambientais e impactos na paisagem.

A chuva é um dos fatores geoambientais de maior importância na erosão dos solos, representa, segundo Boin (2000) uma participação em até $80 \%$ na ocorrência do fenômeno da erosão. O volume precipitado e a velocidade da enxurrada dependem da dinâmica pluviométrica, tais como: intensidade, 
duração e frequência da precipitação. Assim, é fundamental se conhecer a intensidade, pois representa a relação entre as outras duas importantes características: quanto chove (quantitativo) e quando chove (temporal).

A variabilidade e irregularidade das chuvas, assume um papel extraordinariamente decisivo no entendimento da erosividade. Desta forma, o estudo sobre a influência das chuvas, continua a merecer maiores análises climatológicas, destacando a aplicação dos conceitos de climatologia dinâmica, enfocando o papel da chuva na ocorrência do fenômeno da erosão e nas demais formas de degradação dos solos (arenização e desertificação).

De acordo com Silva (2014), a ocorrência de eventos pluviais extremos, a variabilidade pluviométrica e a forte erosividade das chuvas, tem potencializado o processo de degradação ambiental, na área de estudo, que se localiza em Gilbués, município situado no sudoeste do estado do Piauí. Segundo Sales (1998), esse processo tem despertado interesse da comunidade acadêmica e de ambientalistas por apresentar intensa degradação.

Devido à magnitude e elevados níveis de degradação dos solos, a área pesquisada é denominada oficialmente pelo Programa de Ação Nacional de Combate à Desertificação e Mitigação dos Efeitos da Seca como um dos "núcleos de desertificação" do nordeste brasileiro e considerada a maior do tipo no país, com extensão aproximada de $6.131 \mathrm{~km}^{2}$ (BRASIL, 2004).

No entanto, o núcleo de Gilbués apresenta condições climáticas, pedológicas, ecológicas e hidrológicas que o distinguem das áreas suscetíveis à desertificação (ASD). Os núcleos de IrauçubaCE, Cabrobó-PE, Seridó-RN, por exemplo, tem clima semiárido (presença de aridez), pluviosidade inferior a $800 \mathrm{~mm} / \mathrm{ano}$, escassez de recursos hídricos, embasamento cristalino, solos pedregosos e rasos, domínio vegetal da Caatinga e depressões interplanálticas como principal forma de relevo (BRASIL, 2004).

De acordo com Silva (2014), o núcleo de Gilbués possui clima tropical subumido, pluviosidade em torno de $1.200 \mathrm{~mm} / \mathrm{ano}$, predominância de um período chuvoso que se concentra entre os meses de outubro a maio, sendo bem distribuído para uma ASD, embasamento sedimentar, solos profundos constituídos de argila e areia, domínio do Cerrado, chapadas, morros testemunhos e rampas longas como principais feições geomorfológicas

Algumas pesquisas desenvolvidas no âmbito da climatologia (SALES, 1998; SILVA, 2014), apontam avaliações e críticas sobre o enquadramento de Gilbués como ASD. Para Sales (1998), a região está fora das zonas suscetíveis ao fenômeno, por apresentar índices de aridez (IA), que oscilam entre 0,86 a 0,96, bem acima do valor de referência do Programa das Nações Unidas para o Meio 


\section{OS DESAFIOS DA GEOGRAFIA FÍSICA NA FRONTEIRA DO CONHECIMENTO \\ Instituto de Geociências - Unicamp \\ Campinas - SP \\ 28 de Junho à 02 de Julho de 2017}

Ambiente(UNEP). Pela proposta da UNEP, as áreas preferencialmente sujeitas à desertificação teriam índices de aridez inferiores a 0,65.

Silva (2014), ao desenvolver um estudo sobre a dinâmica pluviométrica de Gilbués, considera inadequado a utilização do termo desertificação para caracterizar os processos de degradação ambiental ocorridos em Gilbués, devido às condições climáticas definirem as seguintes características: a) ausência de aridez; b) carência de baixos índices pluviométricos; c) ausência de períodos secos prolongados; c) abundância hídrica (rios perenes e aquíferos) (SILVA, 2014, p.173).

Atualmente, pesquisas realizadas por Silva (2014) em Gilbués, têm adotado o conceito de arenização (SUERTEGARAY, 1987) na tentativa de explicar a dinâmica do processo que ocorre nesta área. O referido processo, se caracteriza por uma extensa área de solo exposto avermelhado com vegetação rasteira desenvolvida de forma raquítica em superfícies levemente onduladas, produzindo na paisagem uma microtopografia do tipo "Badland" conhecida pela comunidade como "grotas" (Figura 1).

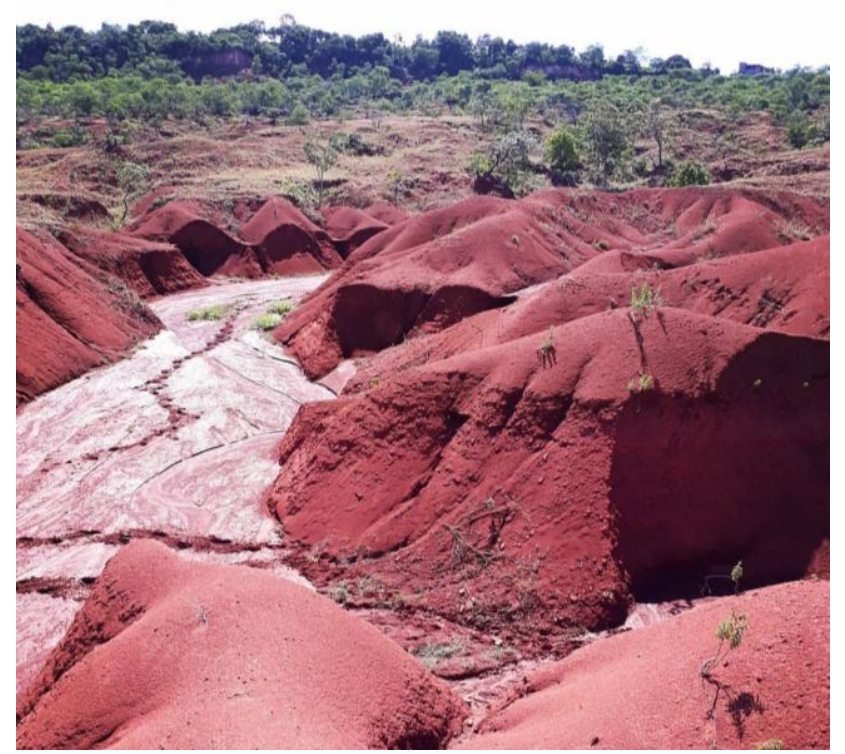

Figura 1 - Grotas/degradação ambiental na paisagem de Gilbués Fonte: Ivamauro Ailton de Sousa Silva, 2017

Esse processo, evidencia a dinâmica e morfogênese acelerada da paisagem. De acordo com Silva (2014, p. 16), são áreas intensamente erodidas pelo vento e pela água das chuvas, que promovem a perda de horizontes superficiais do solo, acarretando formação de feições onduladas de areia e cicatrizes na paisagem. Nessa área, por causa da mobilização de sedimentos, o surgimento da cobertura vegetal e o desenvolvimento de vegetação de porte mais denso ficam bastante comprometidos.

Suertegaray (1992, p. 71) conceitua arenização como "o processo de retrabalhamento de depósitos arenosos pouco ou não consolidados, que promove, nessas áreas, uma dificuldade de fixação da 
cobertura vegetal, devido à intensa mobilidade de sedimentos arenosos pela ação das águas (erosão hídrica) e dos ventos (erosão eólica)".

De acordo com Suertegaray (1992) o processo de arenização está restrito a regiões de climaúmido, embora períodos de estiagem sejam comuns, é um fenômeno que envolve erosão, transportee acumulação. Suertegaray (2001) elucida que a dinâmica dos processos envolvidos na arenização requer disponibilidade de água. Conforme Suertegaray (1992), a elevada precipitação, em particular aquela concentrada em chuvas torrenciais, favorece os processos de escoamento, potencializando a formação de ravinas e voçorocas, feições resultantes do escoamento hídrico.

Verdum (1997) afirma que as precipitações elevadas são um motor do processo dearenização, pois atingem as formações superficiais com fragilidade estrutural, e a cobertura decampo pouco protetora. Essa fragilidade permite a formação de ravinas e voçorocas, querepresentam processos de escoamento retrabalhando os sedimentos, juntamente, com a ação eólica

Nessa persepctiva, a análise do clima como fenômeno geográfico indica uma concepção teórica em que, além dos estudos físicos dos elementos meteorológicos, propõem-se interações com os processos que ocorrem na paisagem, por meio de uma análise integrada, considerando as potencialidades, limitações e vulnerabilidades do ambiente.

Assim, a investigação de episódios pluviométricos extremos, revela sua importância no planejamento ambiental, principalmente acerca das ações sociais, uma vez que, processos de degradação dos solos afetam as atividades socioeconômicas e compromete o bem-estar da população como também podem danificar o ambiente e potencializar os processos erosivos. Neste contexto, a pesquisa tem como objetivo principal: identificar a ocorrência de eventos extremos de precipitação em Gilbués, enfatizando suas interferências no processo de arenização.

\section{Materiais e métodos}

A pesquisa foi realizada em três etapas distintas e complementares. No primeiro momento, procedeuse a revisão bibliográfica sobre o tema e contextualização de conceitos norteadores; no segundo momento levantaram-se dados sobre o regime pluviométrico, definidos conforme a excepcionalidade e quantidade pluvial.

Os dados pluviométricos foram obtidos pela Estação Hidroclimática da Superintendência do Desenvolvimento do Nordeste (SUDENE). Essa etapa possibilitou a elaboração dos pluviogramas (gráficos de precipitação), que equivale numa representação cartográfica que mostram a variação porcentual das precipitações mensais/diárias em relação à precipitação total de cada ano/mês, indicando o mês mais seco e o mês mais úmido e revelando, por meio de um histograma, os totais 
pluviométricos anuais e sua espacialização dos períodos estudados (1964, 1973, 1979, 1980, 1985 e 1994) definidos, principalmente pela quantidade e pelo comportamento excepcional (Quadro 1). Por último foi realizado o trabalho de campo, com intuito de verificar a dinâmica da paisagem perante as condições climáticas (período chuvoso e estiagem).

Quadro 1 - abrangência dos dados da área em estudo

\begin{tabular}{|c|c|c|c|c|c|c|}
\hline Período & 1964 & 1973 & 1979 & 1980 & 1985 & 1994 \\
\hline $\begin{array}{c}\text { Total } \\
\text { pluviométrico }\end{array}$ & $1.190 \mathrm{~mm}$ & $1.867 \mathrm{~mm}$ & $1.400 \mathrm{~mm}$ & $1.717 \mathrm{~mm}$ & $1.496 \mathrm{~mm}$ & $1.495 \mathrm{~mm}$ \\
\hline
\end{tabular}

Elaboração: Ivamauro Ailton de Sousa Silva Fonte dos dados: SUDENE

Os pluviogramas obtidos foram muito úteis, pois auxiliaram na definição dos eventos extremos. Para cada um dos 6 pluviogramas foram feitas análises interpretativas, comparativas e quantitativas, que permitiu o reconhecimento da distribuição da precipitação, bem como a identificação dos períodos com eventos extremos, além de verificar a dinâmica e o comportamento pluviométrico da área pesquisada.

\section{1 Área em estudo: localização e caracterização climática}

A área em estudo localiza-se em Gilbués, município situado no sudoeste do estado do Piauí (Figura 2), distancialmente encontra-se a $742 \mathrm{~km}$ da capital Teresina.

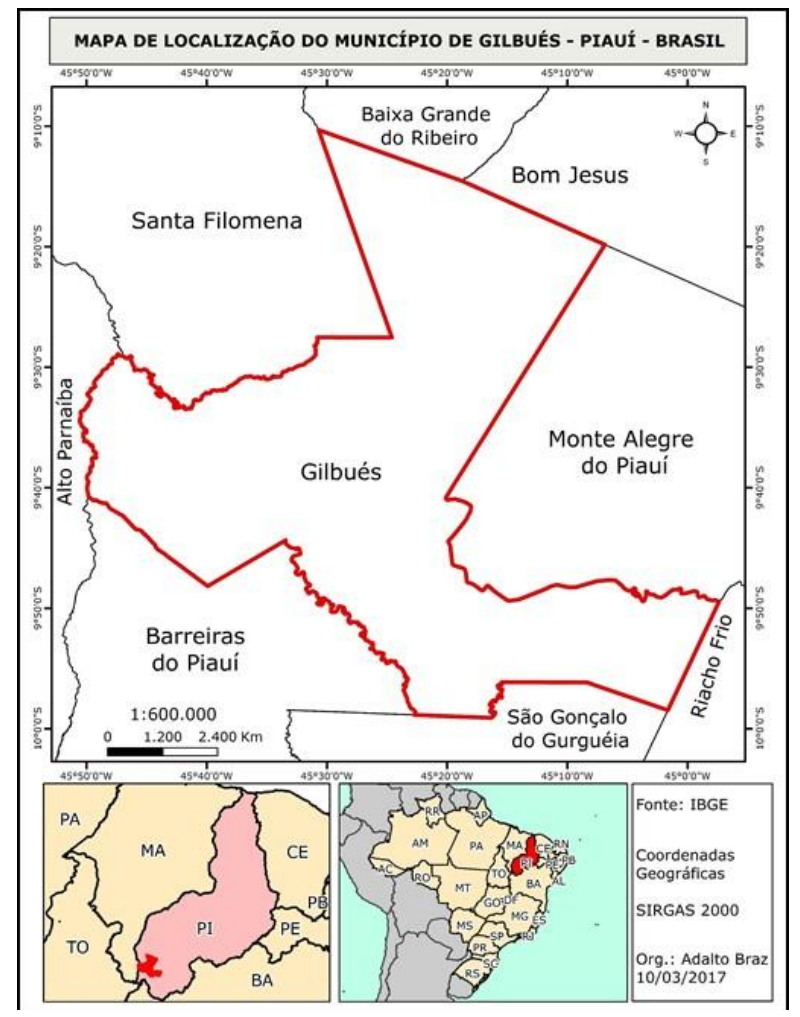

Figura 2 - Localização da área em estudo - munícipio de Gilbués 
A localização geográfica da área de estudo, situada na porção centro ocidental do Nordeste define o caráter climático transicional, refletindo, de acordo com Sales (2003, p. 122) "o contato dos três grandes domínios morfoclimáticos: das caatingas, a leste-nordeste; dos cerrados, a sul-sudoeste; e das florestas tropicais úmidas, a noroeste". Assim, a área de estudo poderia ser interpretada como indicadora da complexidade dos processos atmosféricos dinâmicos.

A área territorial de Gilbués embora seja bastante expressiva, não é suficientemente grande ou particularmente diferenciada, para compor uma dinâmica climática própria, estando inserida no jogo das variações climáticas regionais e continentais. "Os sistemas de circulação atmosférica responsáveis pelo regime e instabilidade de chuvas na região, dois (Zona de Convergência Intertropical e Massa Equatorial Continental) atuam com maior frequência, ao passo que outros dois sistemas atmosféricos (mTa e mEa) operam de forma limitada garantem estabilidade para a região" (SILVA, 2014, p. 87).

Regionalmente, apresenta características do tipo tropical de continentalidade articulada, dotada de um longo período chuvoso durante o ano, opondo-se a outro, mais seco. Diante dessas características, o clima na região é tropical continental subúmido, enquadrando-se na classificação de Köppen-Geiger do tipo Aw, Strahler e Nimer se caracteriza como clima tropical (Quadro 1).

Quadro 1 - Classificação climática apresentada para Gilbués-Piauí

\begin{tabular}{|c|l|l|}
\hline Sistema de classificação & \multicolumn{1}{|c|}{ Tipologia } & \multicolumn{1}{c|}{ Aspectos climáticos } \\
\hline Köppen & $\begin{array}{l}\text { Clima Aw, megatérmico, } \\
\text { com moderada deficiência } \\
\text { hídrica no inverno (4 a 5 } 5 \\
\text { meses). }\end{array}$ & $\begin{array}{l}\text { Tropical com chuvas de verão e com seca no } \\
\text { inverno e com temperaturas médias que variam de } \\
17^{\circ} \mathrm{C} \text { (mínima) a } 40^{\circ} \mathrm{C} \text { (máxima). No período mais } \\
\text { seco apresenta pelo menos um mês com } \\
\text { precipitação inferior a 50 mm (inverno) }\end{array}$ \\
\hline Strahler & Clima Tropical semiúmido & $\begin{array}{l}\text { Tropicalidade sumiúmida, apresenta inverno seco } \\
\text { e verão úmido. }\end{array}$ \\
\hline Nimer & Clima Tropical & $\begin{array}{l}\text { Tropical com duas estações bem definidas } \\
\text { chuvosa e seca) }\end{array}$ \\
\hline
\end{tabular}

Elaboração: Ivamauro Ailton de Sousa Silva

A pluviosidade média anual é definida no regime tropical continental, apresentando, conforme Silva (2014), totais pluviométricos em torno de $1.200 \mathrm{~mm}$, com ampla variação e excepcionalidades no regime e no ritmo das chuvas. Os totais pluviométricos mais significativos, concentram-se entre os meses de outubro a abril (Figura 2). 


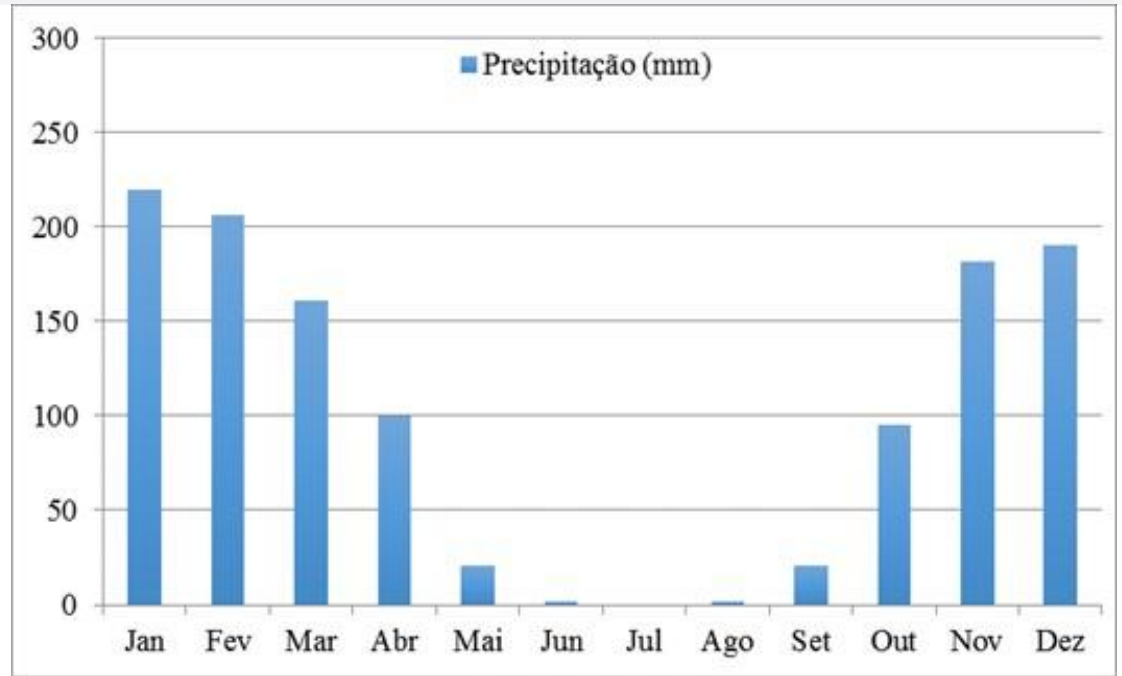

Figura 2 - Gráfico de pluviosidade média 1963-1999

Fonte: SILVA, 2014

O regime pluviométrico, apresenta as seguintes configurações: a) o período de maior pluviosidade vai de novembro a março, que se constituem nos cinco meses mais chuvosos da área de estudo; b) o período de menor pluviosidade compreende os meses de maio a setembro, que podem ser considerados o época da seca, que tem duração variável; c) os três meses mais secos, dentro do quadro pluviométrico são: junho, julho e agosto, já que, os meses de maio e setembro habituam apresentar rarefeita pluviosidade durante o período registrado.

\section{Resultados e discussão}

Em termos regionais, o clima da área em estudo se caracteriza por uma ampla diferenciação, revelada, principalmente, pela distribuição espacial das precipitações no decorrer do ano (Figura 3). 

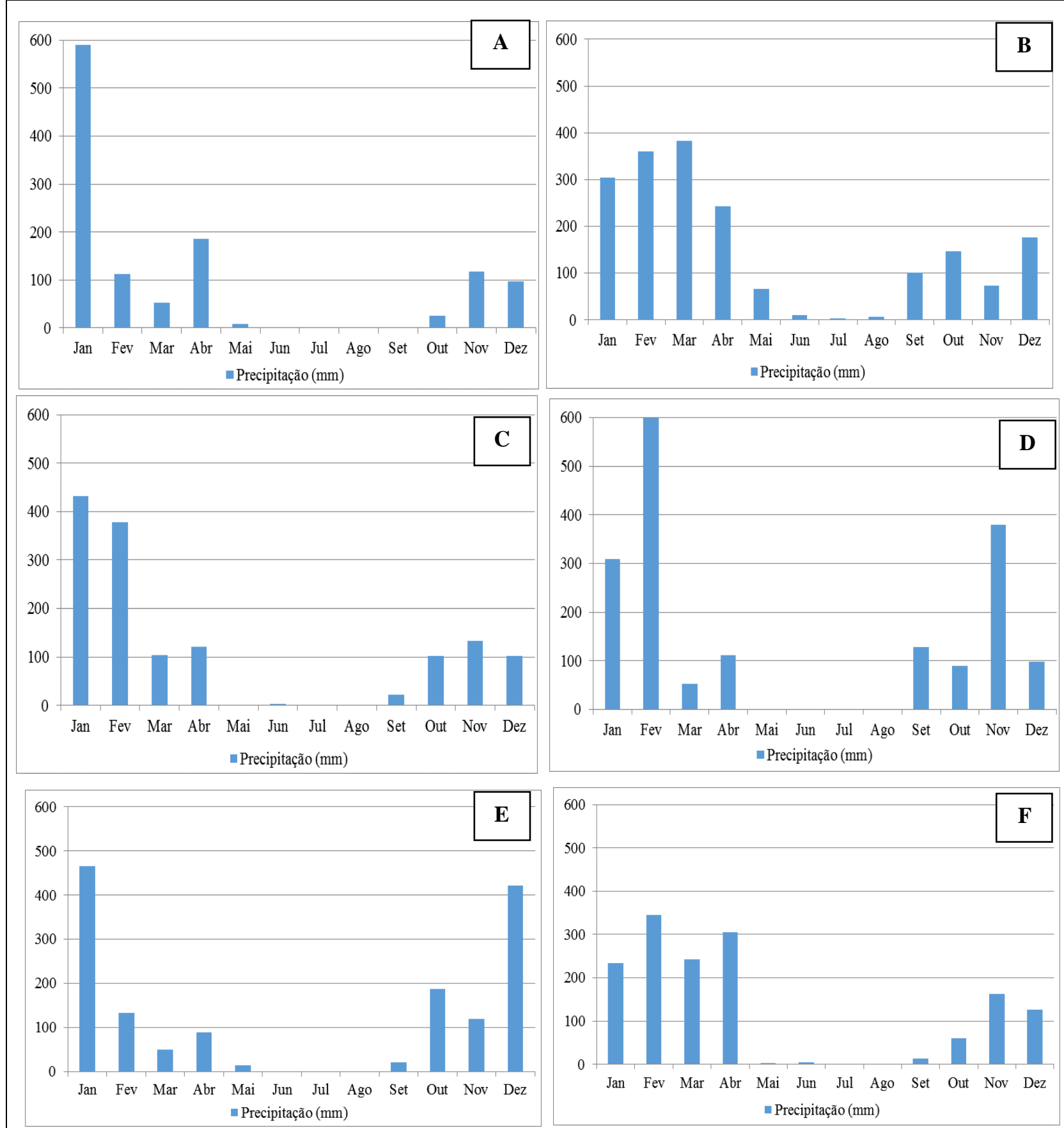

Figura 3 - Gráficos de precipitação: 1964 (A); 1973 (B); 1979 (C); 1980 (D); 1985 (E); 1994 (F) 
A variabilidade pluviométrica da área pesquisada é definida por oscilações na quantidade de chuva apresentando uma dinâmica com períodos de aumento e posteriormente interpolados com anos com declínio pluviométrico. É possível distinguir, quanto às chuvas, duas estações bem definidas, característica das regiões tropicais

Através da representação dos gráficos da figura 3, nota-se, que a dinâmica precipitação se caracteriza, por apresentar alta variabilidade espaço-temporal, com distribuição desigual no decorrer do ano, tanto em escala anual como mensal.

Os gráficos de precitação, demostram, por exemplo a ocorrência de eventos extremos de precipitação, sucedidos principalmente nos meses de janeiro e fevereiros. Em 1964 e 1980, os meses de janeiro e fevereiro atingiu volumes de chuva superiores a $580 \mathrm{~mm}$. Observa-se também, o baixo regime pluvial no período primavera-verão, demostrando uma sucessão recuada dos eventos pluviométricos da área de estudo.

O regime pluviométrico do ano de 1973, atingiu totais de $1.867 \mathrm{~mm}$, sendo o ano mais chuvoso da série-temporal. Em relação aos anos anteriores, foi um ano atípico, pois o volume pluvial apresentou regime excepcional fora dos padrões habituais. Nesse período, a dinâmica pluviométrica foi caracterizada por um curto período de estiagem com a ocorrência de chuvas rarefeitas em junho e agosto e ausência de chuva no mês de julho.

Os dados de pluviosidade, comprovam que, a distribuição pluviométrica da área em estudo, se acumula entre os meses de dezembro-janeiro-fevereiro, períodos em que a chuva se despeja de forma concentrada. Ou seja, exatamente, nesse período a ocorrência de quantidade pluviométricas elevadas, proporciona um poder erosivo maior, tornando a paisagem vulnerável aos processos erosivos em função dos eventos pluviais extremos e intensos.

Considerando a fragilidade ambiental da área pesquisa, a ocorrência de eventos extremos de precipitação,é capaz de alterar as condições/características e também acelerar os processos erosivos que ocorrem na paisagem.Um dos aspectos mais importante é que as "pancadas de chuva" são extremamente agressivas aos solos, aspectos climáticos, tais como: a quantidade elevada, a distribuição espaço-temporal e dias frequentes de muita chuva podem implicar em saturação e remoção do solo.

Assim, no tocante ao quadro pluvial, ocorrerão excedentes hídricos, que vão se acumular na superfície do solo e escoar pelo terreno (Figura 4). Essa dinâmica é capaz de potencializar o escoamento superficial e os fluxos hídricos, causando impactos na paisagem como a redefinição dos canais de drenagens, a perdas de horizontes dos solos, formação de terrenos arenosos, e intensifica o processo de arenização em Gilbués. 


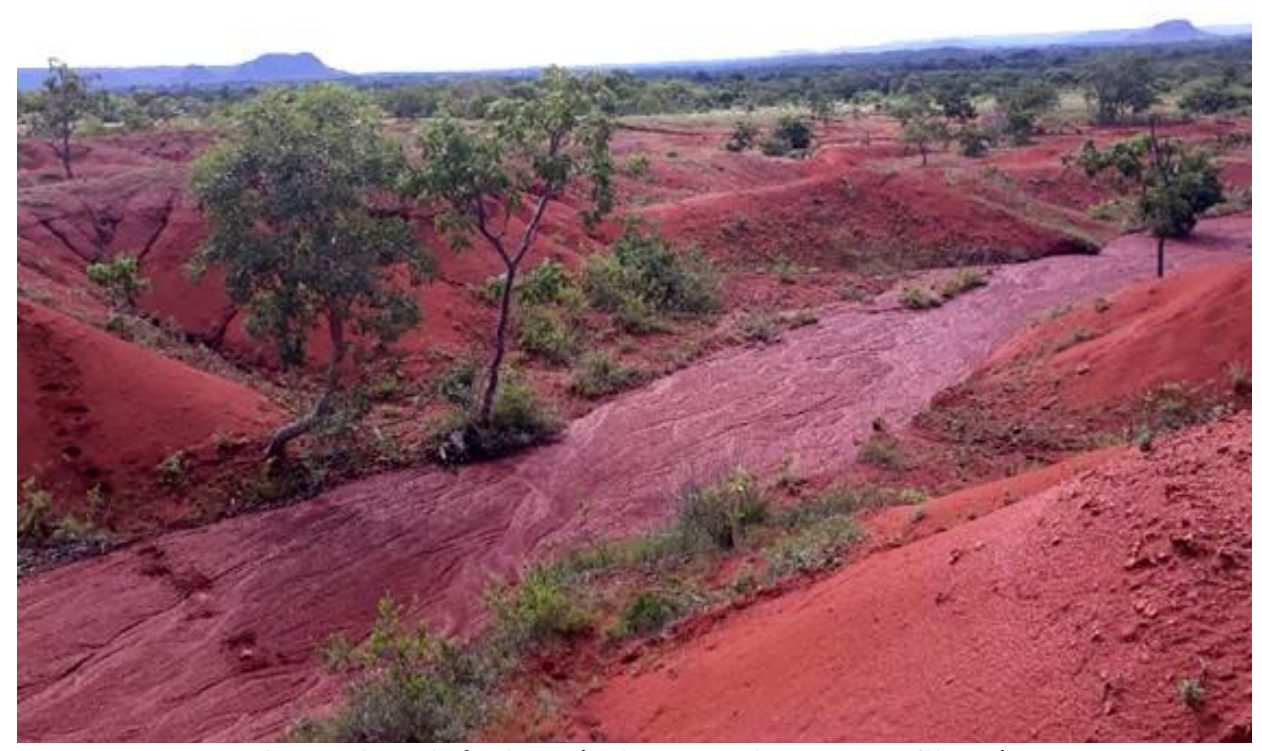

Figura 4 - Dinâmica hídrica na paisagem de Gilbués Fonte: Pesquisa de Campo, 2017

Assim, a interação entre variabilidade climática, eventos extremos de precipitação, dinâmica hídrica e escoamento superficial, atuam na remobilização, desagregação, remoção, transporte, deposição do material areno-argiloso em áreas no entorno de serras e morros, desenvolvendo imensas áreas com solo exposto avermelhado (Figura 5)

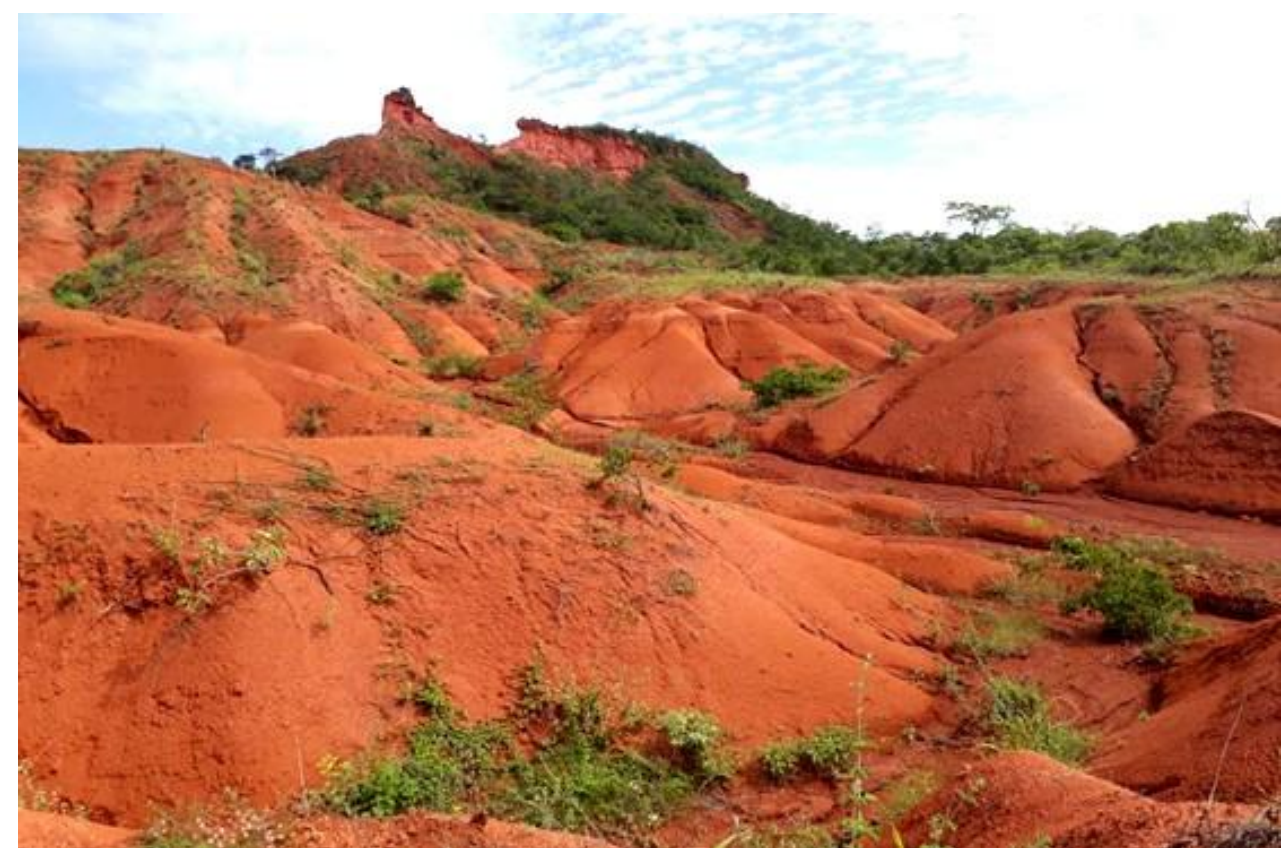

Figura 5 - Arenização em Gilbués

Fonte: Pesquisa de Campo 


\section{OS DESAFIOS DA GEOGRAFIA FÍSICA NA FRONTEIRA DO CONHECIMENTO \\ Instituto de Geociências - Unicamp \\ Campinas - SP \\ 28 de Junho à 02 de Julho de 2017}

Ainda em relação ao comportamento pluviométrico, o agricultor "Manuel Cirqueira" põe tristeza na voz quando fala da chuva, sempre bendita e esperada em qualquer terra do Nordeste:

\footnotetext{
"Aqui, quando começa a chover é triste de ver a água escorrendo. A água abre grandes buracos por todos os lados. A chuva vai lavando a terra e abrindo mais voçorocas".
}

A título de conclusão, o processo de arenização em Gilbués é complexo e se localiza em um ambiente frágil com condições climáticas bem dinâmicas e com alta variabilidade pluviométrica. Sob essas condições, a paisagem se modifica mais rapidamente, alterando as formas das vertentes, tornando os processos morfogéneticos e morfodinâmicos mais intensos.

\section{Considerações finais}

Os pluviogramas apresentados nesta pesquisa foram fundamentais, para revelar o regime pluviométrico de precipitação em Gilbués, pois permitiram uma visão ritmada da distribuição e quantidade das chuvas, especialmente a passagem ininterrupta dos períodos analisados, também auxiliaram na identificação de eventos extremo/excepcionais de precipitação.

O processo de arenização em Gilbués é complexo e se localiza em um ambiente frágil com condições climáticas bem dinâmicas e com alta variabilidade pluviométrica e ainda episódios excepcionais de precipitação. Esse comportamento pluvial é de grande relevância para avaliar os riscos naturais que potencializam o processo de arenização.

Assim, a fragilidade ambiental da paisagem de Gilbués, relaciona-se com a dinâmica climática, que se caracteriza pela presença de eventos chuvosos concentrados e extremos. Isso permite compreender que a chuva em interação com as condições geológicas (arenitos); feições geomorfológicas (comprimento da vertente/rampas longas); constituição pedológica são fatores que contribuem para a gênese e potencialização do processo de arenização na área pesquisada.

\section{Agradecimentos}

O autor agradece a Coordenação de Aperfeiçoamento de Pessoal de Nível Superior (CAPES) pela atual concessão de bolsa no Doutorado na Universidade Federal do Rio Grande do Sul.

\section{Bibliografia}

BOIN, M. N. Chuvas e Erosões no Oeste Paulista: uma análise climatológica aplicada. Rio Claro, UNESP. Tese de Doutorado. 264 p. 2000 
BRASIL. Programa de ação nacional de combate à desertificação e mitigação dos efeitos da seca - PANBrasil. Brasília, DF: Ministério do Meio Ambiente. Secretaria de Recursos Hídricos. 242p. 2004.

KÖPPEN, W.; GEIGER, R. Klimate der Erde. Gotha: Verlag Justus Perthes. 1928

SALES, M. C. L. Degradação Ambiental em Gilbués, Piauí. Revista Mercator. Fortaleza, 02, 04, 115-124. 2003.

SALES, M. C. L. Estudo da degradação ambiental em Gilbués-PI: Reavaliando o "núcleo de desertificação". São Paulo, USP. Dissertação de Mestrado - Geografia. 181p. 1998.

SILVA, I. A. S. Clima e arenização em Gilbués-Piauí: dinâmica das precipitações e a vulnerabilidade da paisagem aos eventos pluviais intensos. 2014. 185 f. Dissertação (Mestrado em Geografia) - Instituto de Estudos Socioambientais, Universidade Federal de Goiás, Goiânia, 2014.

SUERTEGaRAY, D. A.. Deserto Grande do Sul: Controvérsia. Porto Alegre: Editora da Universidade, UFRGS, 1992.

SUERTEGARAY, D. M. A. A trajetória da natureza: um estudo geomorfológico sobre os areais de Quarai, RS. Tese de Doutorado. USP/FFLCH. 243p. 1987.

SUERTEGARAY, D. M. A.; GUASSELli, L. A. e VERDUM, R. (Org.) Atlas da arenização - Sudoeste do Rio Grande do Sul. Porto Alegre/RS: Secretaria da Coordenação e Planejamento. 85 p. 2001.

SUPERINTENDENCIA DE DESENVOLVIMENTO DO NORDESTE - SUDENE. Rede Hidroclimatológica do Nordeste. Disponível em http://pageserver-nt.sudene.gov.br/ixpress/pluviometria/plv/index.dml

UNITED NATIONS ENVIRONMENT PROGRAMME. (2007). Section B: State-and-Trends of the Environment: 1987-2007. In: The fourth report in the Global Environment Outlook (GEO) series: 81-114. Disponivel em: http://www.unep.org/geo/geo4/report/geo-4_report_full_en.pdf. Acessado em: 15 de março de 2017.

VERDUM, R. Approche géographique des deserts dans lês communes de São Francisco de Assis et Manuel Viana - Etat do Rio Grande do Sul - Brésil. 211f. Tese de Doutorado - Université de Toulouse II (Le Mirai), U.T.H, França. 1997 